\title{
NICOLAU SYNDROME: AN IATROGENIC COMPLICATION
}

Preethi Palanimanickam¹, Aditya Kumar Bubna², Mahalakshmi Veeraraghavan³, Anandan Sankarasubramaniam ${ }^{4}$, Sudha Rangarajan ${ }^{5}$

\section{HOW TO CITE THIS ARTICLE:}

Preethi Palanimanickam, Aditya Kumar Bubna, Mahalakshmi Veeraraghavan, Anandan Sankarasubramaniam, Sudha Rangarajan. "Nicolau Syndrome: An Iatrogenic Complication". Journal of Evolution of Medical and Dental Sciences 2014; Vol. 3, Issue 53, October 16; Page: 12375-12377, D0I: 10.14260/jemds/2014/3636

ABSTRACT: Administration of certain drugs may be associated with cutaneous adverse effects. Some of which have classical findings and can be labeled as a syndrome. One such entity is Nicolau syndrome, a clinical condition which at times can be missed if the clinician is unaware of this condition. We hereby present this case report.

KEYWORDS: Embolia cutis medicamentosa, Livedo-like dermatitis.

INTRODUCTION: Nicolau syndrome (embolia cutis medicamentosa) is a severe painful local necrosis at the site of an injected medicament. It may follow intramuscular therapeutic injections and also sclerotherapy. Clinically it is characterized by stellate erythema and infiltration followed by central necrosis that heals with or without scarring.

CASE REPORT: Our patient was a 50 year old gentleman who was referred to us from the Department of General Surgery with a purple colored extremely painful patch over the buttocks (Figures 1 and 2). He gave a history of the administration of Injection Diclofenac intramuscularly in the right gluteal region following an episode of pain over the left knee joint.

A day later he developed an ecchymotic, painful and necrotic lesion over the injected site which gradually progressed to involve the entire gluteal region and the adjacent flanks over a period of five days. The lesion was extremely tender. There was no history of hot or cold compresses to that area, nor was there any history of bleeding disorder. Systemically the patient had no ailments.

Based on the history and the clinical findings a diagnosis of Nicolau syndrome was made and the patient was counseled about the condition and its likely clinical course. As the presentation was mild the patient was started on Tablet Ciprofloxacin 500mg twice daily as a precaution to prevent secondary infection, Tablet Pentoxyphylline 400mg twice daily, topical heparin gel application twice daily and a multivitamin supplement with $55 \mathrm{mg}$ of elemental zinc once daily to facilitate wound healing.

The patient was under observation. His lesions gradually improved and he was discharged. However he was subsequently lost to follow up. 


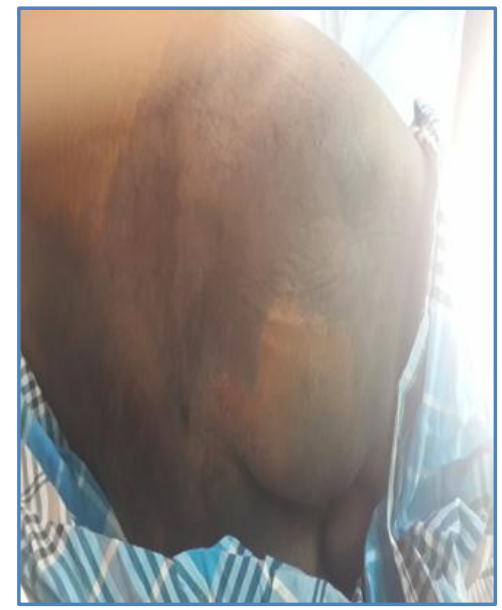

Figure 1

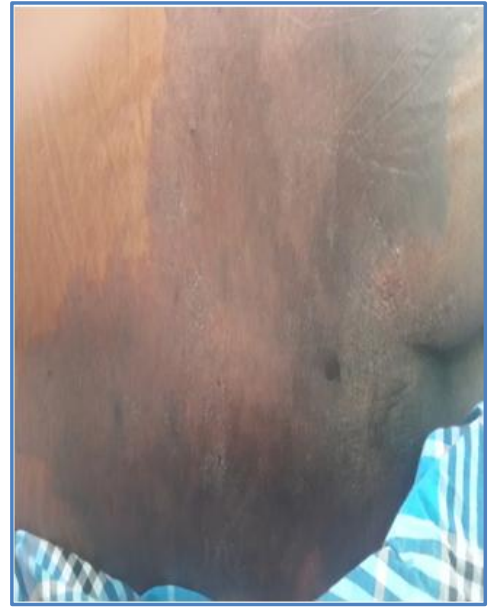

Figure 2

DISCUSSION: Nicolau Syndrome also known as livedo like dermatitis and Embolia cutis medicamentosa was first described in 1924 by Freudenthal and in 1925 by Nicolau in patients receiving bismuth salts for the treatment of Syphilis.[1] Other drugs precipitating Nicolau syndrome include penicillins, non-steroidal anti-inflammatory drugs like piroxicam and diclofenac, local anesthetics like lidocaine, antipsychotics, antiepileptics and glatiramer acetate.[2,3,4]

Rarely sclerotherapy may be a cause for Nicolau syndrome.[5] The pathogenesis of Nicolau syndrome has not been clearly elucidated. The most common hypothesis suggested is the direct irritation of the vasculature, owing to arterial embolism, caused by the drug along with drug crystallization with the development of arteriovenous shunt and ischemia secondary to para-arterial injection. ${ }^{[6]}$ Other proposed theories include end artery damage, sympathetic stimulation followed by vascular spasm which in turn leads to necrosis.

Clinically the lesions of Nicolau syndrome are pathognomonic. It is characterized by severe pain at the injection site followed by erythema and progression to a hemorrhagic lesion.[7] This is followed by necrosis of skin and the underlying hypodermis and muscles. Healing occurs by scar tissue formation which takes several months. Early institution of treatment helps prevent skin necrosis.[8]

Nicolau syndrome though not an uncommon disorder, can be prevented by aspirating just before injecting to ensure the extra-arterial injection of the drug. The upper and outer quadrant of the gluteal region is the preferred site because of fewer large blood vessels. Other technique advocated could be a Z-track method. ${ }^{[9]}$ However it is doubtful whether Nicolau syndrome can be prevented by this method as vascular spasm in Nicolau syndrome is difficult to recognize.[10]

Differentiating Nicolau syndrome from Necrotizing fasciitis is important as in the severe forms of Nicolau syndrome it may closely mimic Necrotising fasciitis and the management of Necrotising fasciitis would be more aggressive with extensive debridement, antibiotics and Intravenous immunoglobulins.

In most cases Nicolau syndrome heals with atrophic scars or pigmentation. In rare cases complications such as hypoesthesia and sepsis can occur. 
Clinicians should therefore be aware of this condition as a diagnostic possibility for anyone presenting with localized pain following intramuscular injection of any substance.

\section{REFERENCES:}

1. Kohler LD, Schwedler S, Worret WI. Embolia cutis medicamentosa. Int J Dermatol. 1997; 36: 197.

2. Bosca I, Bosca M, Belenguer A, Evole M, Hernandez M, Casanova B, et-al. Necrotising cutaneous lesions as a side effect of glatiramer acetate. J Neurol.2006; 253: 1370-1.

3. Harde V, Schwarz T. Embolia cutis medicamentosa following subcutaneous injection of glatiramer acetate. J Dtsch Dermatol Ges.2007; 5: 1122-3.

4. Feldmann R, Schierl M, Rauschka H, Sator PG, Breier F, Steiner A. Necrotising skin lesions with involvement of muscle tissue after subcutaneous injection of glatiramer acetate. Eur JDermatol.2009; 19: 385.

5. Nirmal B, Segu SS, Sachidanand SA, Deshpande P. Nicolau syndrome following sclerotherapy for pyogenic granuloma. Indian J Dermatol Venerol Leprol 2014; 80; 484.

6. Schroter K, Lorenz K. [Nicolau syndrome, form of drug -induced embolism. (Clinical picture etiology and pathogenesis - prevention - comparison with Hoigne syndrome)]. Z Arztl Fortbild (Jena) 1971; 65: 725-31.

7. Senel E, Ada S, Gulec AT, Caglar B. Nicolau Syndrome aggravated by cold application after i.m. diclofenac. J Dermatol. 2008; 35: 18-20.

8. Geukens J, Rabe E, Bieber T. Embolia cutis medicamentosa of the foot after sclerotherapy. Eur J Dermatol. 1999; 9: 132-3.

9. Kim SK, Kim TH, Lee KC, Nicolau syndrome after intramuscular injection: 3 cases. Arch Plast Surg 2012; 39: 249-52.

10. KC Nischal, HB Basavraj, MR Swaroop, DP Agarwal, BD Sathyanarayana, NP Umashankar. Nicolau Syndrome: An Iatrogenic Cutaneous Necrosis. J Cutan Aesthet Surg. 2009; 2: 92-5.

\section{AUTHORS:}

1. Preethi Palanimanickam

2. Aditya Kumar Bubna

3. Mahalakshmi Veeraraghavan

4. Anandan Sankarasubramaniam

5. Sudha Rangarajan

\section{PARTICULARS OF CONTRIBUTORS:}

1. Resident, Department of Dermatology, Sri Ramachandra University, Chennai.

2. Assistant Professor, Department of Dermatology, Sri Ramachandra University, Chennai.

3. Professor, Department of Dermatology, Sri Ramachandra University, Chennai.

4. Professor, Department of Dermatology, Sri Ramachandra University, Chennai.
5. Professor and Head of the Department, Department of Dermatology, Sri Ramachandra University, Chennai.

\section{NAME ADDRESS EMAIL ID OF THE} CORRESPONDING AUTHOR:

Dr. Preethi Palanimanickam,

49, P. S. Puram,

Srinivasapuram,

Tanjavur - 9.

Email: malar6800@gmail.com

Date of Submission: 24/09/2014.

Date of Peer Review: 25/09/2014.

Date of Acceptance: 11/10/2014.

Date of Publishing: 16/10/2014. 